\title{
Small Angle X-ray Scattering Studies of Fe-Si-Cu-B Melt-Spun Ribbons
}

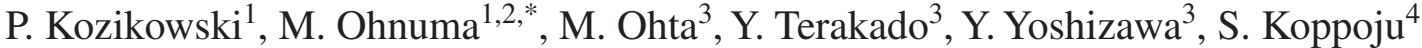 \\ and M. Lewandowska ${ }^{5}$ \\ ${ }^{1}$ Faculty of Engineering, Hokkaido University, Sapporo 060-8628, Japan \\ ${ }^{2}$ National Institute for Materials Science, Tsukuba 305-0047, Japan \\ ${ }^{3}$ Hitachi Metals Ltd., Osaka 618-0013, Japan \\ ${ }^{4}$ International Advanced Research Center for Powder Metallurgy and New Materials (ARCI), Balapur PO, Hyderabad, 500005, AP, India \\ ${ }^{5}$ Faculty of Materials Science and Engineering, Warsaw University of Technology, Woloska 141, 02-504 Warsaw, Poland
}

\begin{abstract}
Nanocrystalline ribbons of $\mathrm{Fe}-\mathrm{Cu}-\mathrm{Si}-\mathrm{B}([\mathrm{Fe}]=76.5-80.7$ at $\%)$ were produced by rapid quenching and subsequent annealing to obtain higher saturation magnetization. To control the thickness of the ribbons, different quenching rates were applied. The magnetic properties, even after annealing, show clear differences depending on the thickness. To understand the origin of these differences, small angle X-ray scattering (SAXS) measurements were acquired to investigate and quantify changes in the microstructures of samples of different thicknesses, with and without annealing. Since crystallization kinetics were strongly affected by sample thickness (e.g., quenching rate), the volume fraction in samples with different thickness but the same composition were varied in addition to the average size of the bcc crystals. Balancing the average size and the volume fraction gives the optimum sample thickness for obtaining the best soft magnetic properties in the $\mathrm{Fe}-\mathrm{Cu}-\mathrm{Si}-\mathrm{B}$ ribbons. [doi:10.2320/matertrans.M2017046]
\end{abstract}

(Received February 22, 2017; Accepted April 10, 2017; Published May 19, 2017)

Keywords: annealing, grain growth, soft magnetic alloys, rapid quenching, nanocrystalline alloy ribbon

\section{Introduction}

Fe-Si-B-Nb-Cu-type alloys were the first to show soft magnetic properties by generating nano-scale size grains ${ }^{1)}$. This was in direct opposition to the traditional thinking for Fe-Si-type steels wherein larger grains are better for obtaining magnetic softness ${ }^{2}$. The mechanism of the soft magnetic properties of the nanocrystalline alloys has been explained by the "random anisotropy model" proposed by Herzer ${ }^{3,4)}$ soon after the first report of nanocrystalline FINEMET-type alloys ${ }^{5)}$.

Since that time, many compositional derivatives, such as $\mathrm{Fe}-\mathrm{Zr}-\mathrm{B}-\mathrm{Cu}$, have been proposed by different groups ${ }^{6)}$. Although the compositional range varies widely, there are common features to these alloys. They have a frame-like composition generating the amorphous state, with various elements added- one to destabilize the amorphous structure (ex. $\mathrm{Cu}$ ) and the other to stabilize the amorphous phase (ex. Nb). Addition of the destabilizer stimulates a high nucleation rate of the bcc phase by forming clusters (or some other mechanism) and the stabilizer suppresses the growth of particles ${ }^{7)}$. The competition between the two different effects brings about nanoscale microstructures relatively easily. This is advantageous for industrial-scale production; however, the addition of those minor elements can be a barrier to increasing the $\mathrm{Fe}$ content required to obtain higher saturation magnetization. Attempts to produce nanocrystalline alloys with Fe concentrations higher than 80 at $\%$ have been made mainly by suppressing the amount of stabilizing elements and controlling the quenching rate in order to skip any further annealing processes. Although some show promising results with respect to properties, process sensitivity can be a problem, and therefore, some of these new compositions require post annealing $^{8)}$. However, quantitative evaluation of the dependence of

*Corresponding author, E-mail: ohnuma.masato@eng.hokudai.ac.jp the microstructures on the quenching and post annealing process has not yet been obtained ${ }^{9,10)}$. In this paper, quantitative microstructure information (average size, $\mathrm{D}_{\text {ann }}$ and volume fraction, $V_{f}$, of the bcc phase) for a series of Fe-Si-B-Cu-type alloys having different compositions and thicknesses (i.e., quenching processes) is presented. Ribbons with and without annealing were measured via small-angle X-ray scattering (SAXS) and their magnetic properties compared in an effort to understand the origin of the process sensitivity and magnetic properties of these alloys.

\section{Experimental Procedure}

The nanocrystalline alloys were prepared by Hitachi Metals. Two series of amorphous, $5 \mathrm{~mm}$ wide $\mathrm{Fe}-\mathrm{Cu}-\mathrm{Si}-\mathrm{B}$ ribbons were manufactured via a single-roller melt-spinning technique to investigate the influence of $\mathrm{Cu}$ and $\mathrm{B}$ on the crystallization process. Each set included 3 alloys of the following compositions: $\mathrm{Fe}_{80.7-\mathrm{x}} \mathrm{Cu}_{1.3+\mathrm{x}} \mathrm{Si}_{4} \mathrm{~B}_{14}(\mathrm{x}=0,0.1,0.2$ at $\%)$ and $\mathrm{Fe}_{80.5-\mathrm{x}} \mathrm{Cu}_{1.5} \mathrm{Si}_{8} \mathrm{~B}_{10+\mathrm{x}}(\mathrm{x}=0,2,4$ at\%). Each composition was quenched with different quenching rates yielding samples of different thicknesses. After quenching, each specimen was annealed at $450^{\circ} \mathrm{C}$ for 30 minutes in $\mathrm{N}_{2}$ to develop nano-scale grains. Table 1 shows composition, thickness, coercivity, and saturation magnetic flux density for annealed samples. Coercivity $\left(\mathrm{H}_{\mathrm{c}}\right)$ and magnetic induction $\left(\mathrm{B}_{8000}\right)$ were determined from the DC hysteresis loop. The thickness of the samples was determined using the following equation:

$$
I=I_{0} \exp (-\mu t)
$$

where $I$ is emergent intensity, $I_{0}$ is incident intensity, $\mu$ is linear absorption coefficient and $t$ is the sample thickness. In addition thickness has been also confirmed using micrometer gauge, but since it includes the effects of roughness, the values obtained from absorption calculations has been used in subsequent calculations. 
The SAXS experiments were carried out using two of the laboratory SAXS systems at the National Institute for Materials Science (NIMS). A Bruker NANOSTAR using $\mathrm{Cr} \mathrm{K}_{\alpha}(\lambda=$ $0.22 \mathrm{~nm}$ ) radiation with a Goebel mirror and a two dimensional multiwire detector (Bruker HI-STAR) was used to record the low-q region (from 0.07 to $1 \mathrm{~nm}^{-1}$ ). To measure the q region from 0.2 to $7 \mathrm{~nm}^{-1}$, a high-flux/high-transmission Mo $\mathrm{K} \alpha(\lambda=0.07 \mathrm{~nm})$ SAXS system with a two-dimensional confocal mirror (Rigaku NANO-Viewer) and a two-dimensional solid-state detector (Pilatus) was used. The beam diameter at the sample position was smaller than $1 \mathrm{~mm}$ in both cases.

Wide angle X-ray scattering (WAXS) measurements were performed using a Rigaku micro diffraction goniometer with $\mathrm{Cr} \mathrm{K}_{\alpha}$ radiation at a fixed incident angle of $10^{\circ}$. Each sample was measured from both sides (wheel and air side) to check the heterogeneity of the grain size throughout the thickness of the ribbon.

TEM samples were prepared on a Gatan 691 Precision Ion Polishing System (PIPS) using a Focused Ion Beam (FIB). Ion polishing was performed using a beam energy of $4 \mathrm{kV}$ at $8^{\circ}$. TEM observations were carried out on a JEOL 1200 with an acceleration voltage of $120 \mathrm{kV}$. The microstructure was quantitatively analyzed in terms of grain size.

\section{Results}

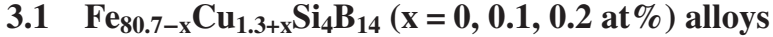

The magnetic properties of the different ribbons with different thicknesses are listed in Table 1. All of the values are for the alloys after annealing, and thickness dependence is clearly shown. The corresponding SAXS profiles are shown in Fig. 1. Although the profiles show differences depending on the composition of the alloy, they have two common fea-

Table 1 Composition, sample thickness (t), magnetic properties of alloys studied, mean grain diameter (D), standard deviation $(\sigma)$ and volume fraction $\left(\mathrm{V}_{\mathrm{f}}\right)$ for post-annealed samples.

\begin{tabular}{|c|c|c|c|c|c|c|c|c|c|}
\hline Composition & $\begin{array}{c}\mathrm{t} \\
{[\mu \mathrm{m}]}\end{array}$ & $\begin{array}{c}\mathrm{H}_{\mathrm{c}} \\
{[\mathrm{A} / \mathrm{m}]}\end{array}$ & $\begin{array}{c}\mathrm{B}_{8000} \\
{[\mathrm{~T}]}\end{array}$ & $\begin{array}{l}D_{\text {cast }} \\
{[\mathrm{nm}]}\end{array}$ & $\sigma_{\text {cast }}$ & $\mathrm{V}_{\mathrm{f} \text {, cast }}$ & $\begin{array}{c}D_{a n n} \\
{[\mathrm{~nm}]}\end{array}$ & $\sigma_{\text {ann }}$ & $V_{f, a n n}$ \\
\hline & 20.2 & 9.6 & 1.74 & - & - & - & 26 & 0.47 & $67 \%$ \\
\hline \multirow[t]{3}{*}{$\mathrm{Fe}_{80.7} \mathrm{Cu}_{1.3} \mathrm{Si}_{4} \mathrm{~B}_{14}$} & 23.5 & 6.6 & 1.75 & 10 & 0.82 & $8 \%$ & 20 & 0.40 & $59 \%$ \\
\hline & 26.3 & 24 & 1.71 & 10 & 0.64 & $51 \%$ & 11 & 0.60 & $70 \%$ \\
\hline & 15.7 & 16.1 & 1.75 & - & - & - & 56 & 0.87 & $70 \%$ \\
\hline \multirow[t]{3}{*}{$\mathrm{Fe}_{80.6} \mathrm{Cu}_{1.4} \mathrm{Si}_{4} \mathrm{~B}_{14}$} & 16.7 & 6.2 & 1.76 & 7 & 0.52 & $3 \%$ & 21 & 0.48 & $69 \%$ \\
\hline & 17.8 & 5.2 & 1.76 & 10 & 0.46 & $8 \%$ & 19 & 0.54 & $64 \%$ \\
\hline & 14.6 & 9.4 & 1.75 & 11 & 0.44 & $3 \%$ & 17 & 0.3 & $46 \%$ \\
\hline \multirow[t]{3}{*}{$\mathrm{Fe}_{80.5} \mathrm{Cu}_{1.5} \mathrm{Si}_{4} \mathrm{~B}_{14}$} & 16.2 & 9.2 & 1.73 & 12 & 0.4 & $9 \%$ & 16 & 0.4 & $54 \%$ \\
\hline & 17.9 & 16.4 & 1.71 & 13 & 0.36 & $8 \%$ & 15 & 0.46 & $62 \%$ \\
\hline & 22.1 & 15.7 & 1.64 & - & - & - & 43 & 0.4 & $65 \%$ \\
\hline \multirow[t]{3}{*}{$\mathrm{Fe}_{76.5} \mathrm{Cu}_{1.5} \mathrm{Si}_{8} \mathrm{~B}_{14}$} & 28 & 7.8 & 1.61 & 11 & - & - & 26 & 0.3 & $50 \%$ \\
\hline & 31.1 & 18.8 & 1.56 & 17 & - & - & 19 & 0.43 & $65 \%$ \\
\hline & 20 & 13.2 & 1.65 & - & - & - & 44 & 0.43 & $81 \%$ \\
\hline \multirow[t]{3}{*}{$\mathrm{Fe}_{78.5} \mathrm{Cu}_{1.5} \mathrm{Si}_{8} \mathrm{~B}_{12}$} & 22.6 & 7 & 1.69 & 10 & - & - & 25 & 0.35 & $81 \%$ \\
\hline & 25.2 & 8.2 & 1.61 & 11 & - & - & 25 & 0.35 & $70 \%$ \\
\hline & 17.7 & 36.1 & 1.73 & - & - & - & 36 & 0.46 & $75 \%$ \\
\hline \multirow[t]{2}{*}{$\mathrm{Fe}_{80.5} \mathrm{Cu}_{1.5} \mathrm{Si}_{8} \mathrm{~B}_{10}$} & 20.4 & 13.3 & 1.74 & - & - & - & 21 & 0.44 & $35 \%$ \\
\hline & 23.4 & 24 & 1.75 & 6 & - & $23 \%$ & 11 & 0.66 & $57 \%$ \\
\hline
\end{tabular}

tures: the thinnest ribbons show the weakest scattering intensity over almost the entirety of the q region observed for the as-quenched state, and the strongest intensity in the low-q region for the ribbons after annealing. The intensity difference in the as-quenched ribbons clearly indicates that the extent of heterogeneity is lowest in the thinnest ribbons and largest in the thickest ribbons. At this stage, XRD analysis shows a diffuse halo indicating an amorphous single phase (Fig. 2). Except for the thinnest ribbons, XRD observations show formation of a nano-size bcc phase, also shown in Fig. 2. In those thicker ribbons, SAXS shows a much stronger scattering intensity, corresponding to a heterostructure of a few $10 \mathrm{~nm}$ or less. Therefore, the origin of the scattering is the presence of the bcc nanocrystals.

In contrast to the as-quenched samples, all of the ribbons (including the thinnest ones) show stronger scattering after than before annealing, which indicates that the volume fraction of the bcc phase increases. In addition, the order of the intensity inverts; i.e., highest for the thinnest ribbons in the low-q region. This indicates that either the size and/or volume of the bcc particles is largest in the thinnest ribbons. Similar to a Bragg peak width analysis, the width of a SAXS profile is also indicative of size, and a rough evaluation of profile shape suggests that the thickest ribbons have the finest size after annealing. This is the opposite of what is expected from the magnetic properties.

\section{2 $\mathrm{Fe}_{80.5-\mathrm{x}} \mathrm{Cu}_{1.5} \mathrm{Si}_{8} \mathrm{~B}_{10+\mathrm{x}}(\mathrm{x}=\mathbf{0 , 2}, 4$ at\% $)$ alloys}

Compared to the previous series, the SAXS profiles of this series after annealing show a second hump in the $1-2 \mathrm{q} \mathrm{nm}^{-1}$ region (Fig. 3), indicating two size distributions. This hump has been interpreted as nanocrystalline copper clusters and becomes visible when nanocrystalline Fe grains become large. If the size difference between the two phases is large enough, one can distinguish two scattering profiles on SAXS otherwise they will overlap. Other than these features, the order of intensity is the same; i.e., lowest over the entire q range for the thinnest ribbons before annealing, and highest for those after annealing in the low-q region. The results again show very clearly that bcc grain size is largest in the thinnest ribbons after annealing, although it is nearly uniform in the as-quenched ribbons.

\section{Discussion}

The SAXS profiles give a rough idea of the microstructures; i.e., the grain size is largest in the thinnest ribbons and finest in the thickest ribbons after annealing. Such a strong size dependence following identical heat treatment upon initial production is uncommon. It is also unusual that the order of the intensity before annealing changes after annealing. This inversion strongly suggests that the bcc crystals formed during quenching are somehow prevented from growing. From a random anisotropy model, it is also odd that the size of the bcc grains is the smallest in the thickest ribbons, since they do show poorer magnetic softness. Therefore, further analysis of the SAXS profiles is required. Since most of the profiles show maxima, which correspond to interparticle interference, the "local mono-disperse hard sphere model" which has been applied to several nanostructured systems 

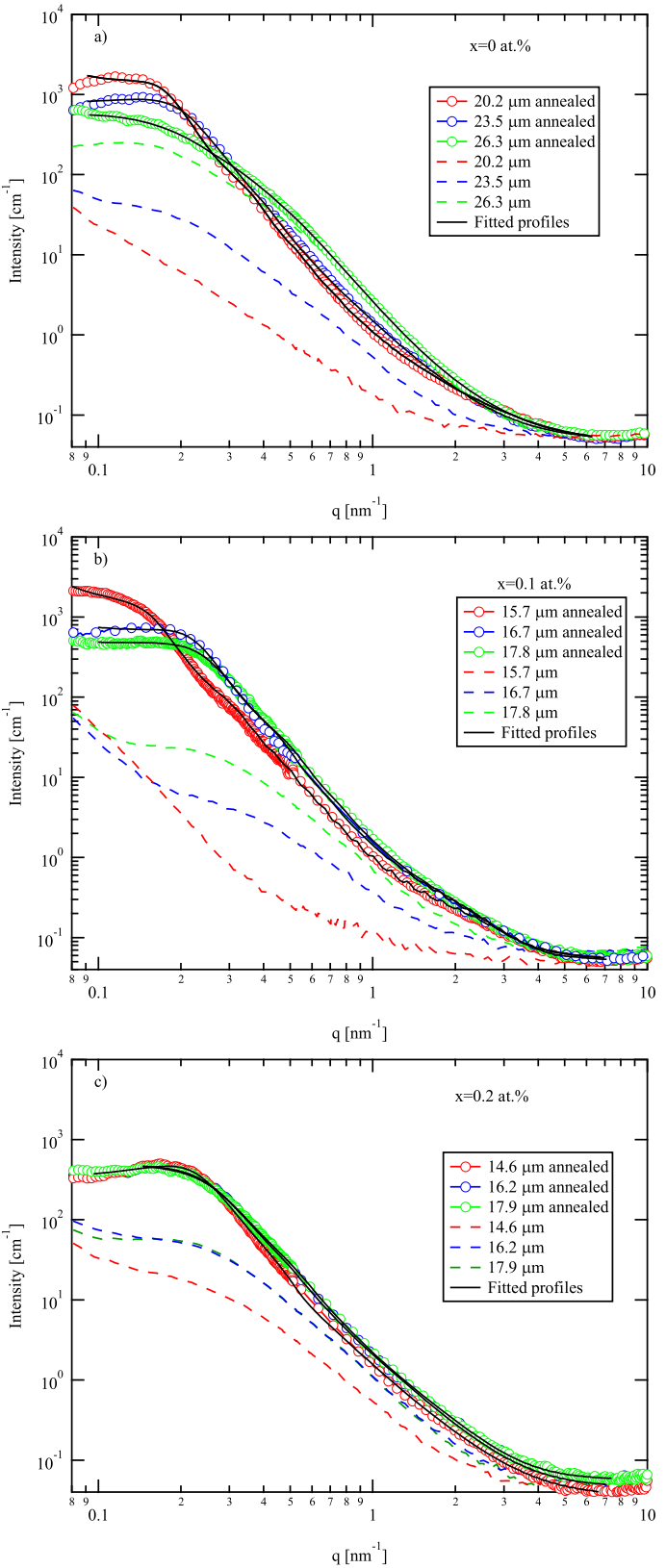

Fig. 1 SAXS profiles of $\mathrm{Fe}_{80.7-\mathrm{x}} \mathrm{Cu}_{1.3+\mathrm{x}} \mathrm{Si}_{4} \mathrm{~B}_{14}(\mathrm{x}=0,0.1,0.2$ at $\%)$ in the as-quenched state (broken lines) and after annealing (circles).

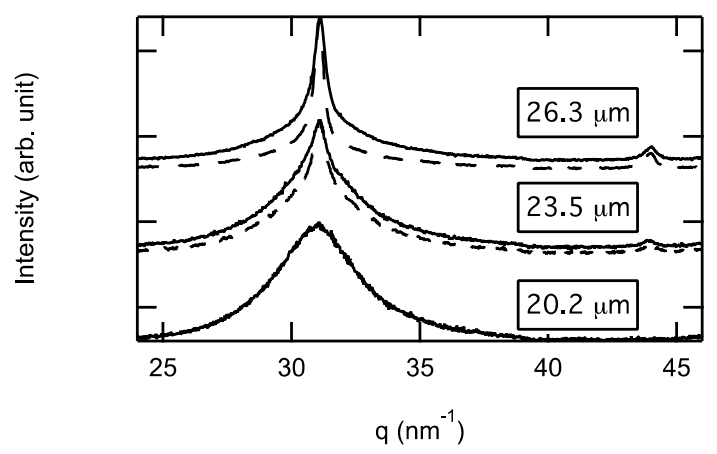

Fig. 2 XRD pattern of $\mathrm{Fe}_{80.7} \mathrm{Cu}_{1.3} \mathrm{Si}_{4} \mathrm{~B}_{14}$ in the as-quenched state. Solid lines are air side; broken lines are wheel side.
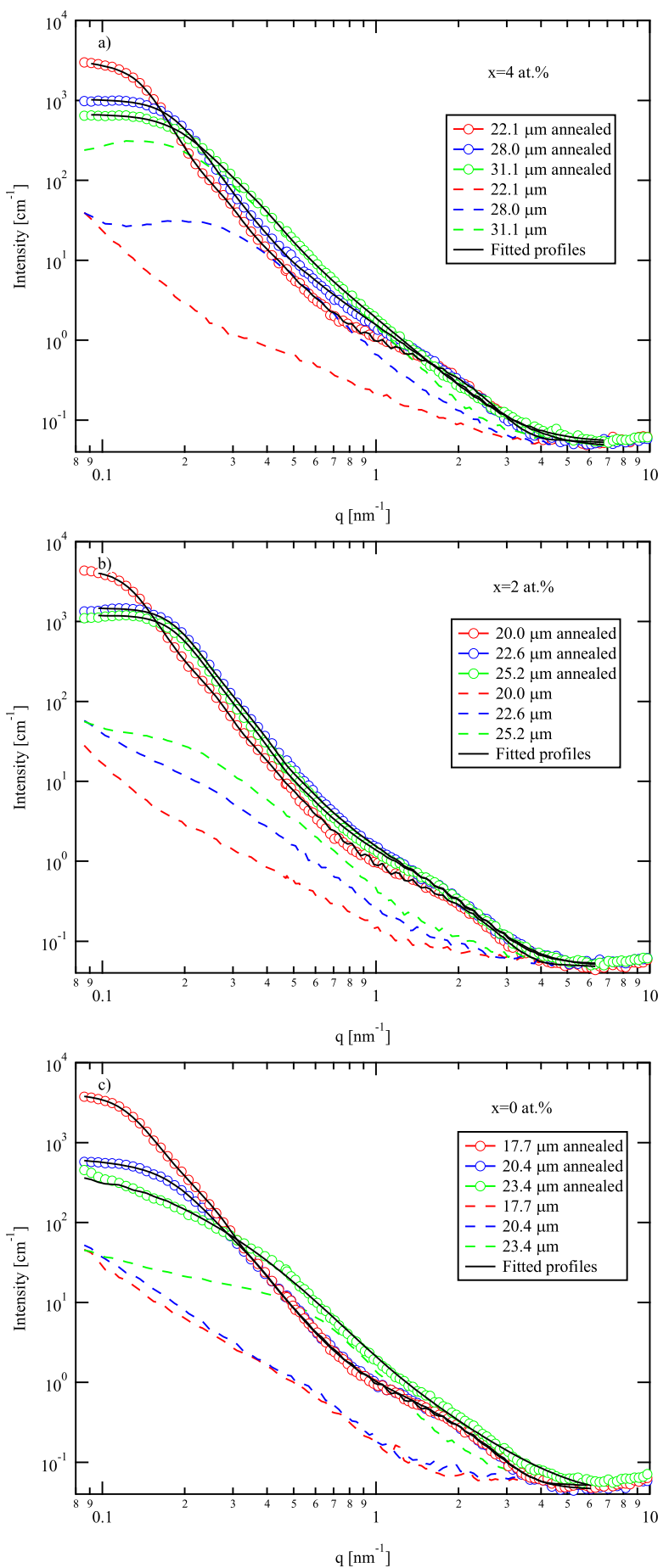

Fig. 3 SAXS profiles of $\mathrm{Fe}_{80.5-\mathrm{x}} \mathrm{Cu}_{1.5} \mathrm{Si}_{8} \mathrm{~B}_{10+\mathrm{x}}(\mathrm{x}=0,2,4 \mathrm{at} \%)$ in the asquenched state (broken lines) and after annealing (circles).

was employed here:

$$
\begin{gathered}
I(q)=\Delta \rho^{2} d_{N} \int_{0}^{R} N(r) V(r) F(q, r) S\left(q, r_{H S}, \eta\right) d r \\
r_{H S}=A \cdot r(A \geq 1)
\end{gathered}
$$

where $R_{H S}$ and $\eta$ is the radius and volume fraction of the hard spheres for determining structure factor, $S\left(q, r_{H S}, \eta\right)$. The detail about the model is described in Ref. 11).

In this model, a form factor is used for spherical particles and log-normal size distributions. The fitted results are shown 
in Figs. 1 and 3 (only for ribbons after annealing, for simplicity). To prove the validity of the fitting, the results of the size distributions evaluated via TEM and SAXS for some alloys are compared. For example, the size distribution of the $\mathrm{Fe}_{80.7} \mathrm{Cu}_{1.3} \mathrm{Si}_{4} \mathrm{~B}_{14}$ ribbons after annealing is shown in Fig. 4, together with the TEM micrographs. Since they show identical results and SAXS has the great advantage of being able to obtain statistic representative values from a much bigger volume, the SAXS values are used in the following discussion.

Figure 5 shows the relationship between average size (obtained by SAXS) and thickness. It is clear that $\mathrm{D}_{\text {ann }}$ is minimized in the thickest of the post-annealed ribbons. (The $\mathrm{D}_{\mathrm{ann}}$ values are also listed in Table 1.) Figure 6 shows the relationship between $H_{c}$ and $D_{a n n}$. These two figures indicate that the magnetic properties for the medium and thinnest ribbons follow a random anisotropy model, where the smaller average size gives a lower $\mathrm{H}_{c}$, while the dependence of $\mathrm{D}$ is about $\mathrm{D}^{2}$.

To understand why the thickest ribbons demonstrate this unexpected relationship between $\mathrm{H}_{\mathrm{c}}$ and $\mathrm{D}_{\mathrm{ann}}$, other important parameters such as volume fraction must be examined. In SAXS analysis, if the scattering length density $(\rho)$ for the residual amorphous and bcc phases are known, the volume fraction can be derived from the intensity in absolute unit measurements and eq. (1). Values of $\rho_{\text {bcc }}$ and $\rho_{\text {matrix }}$ can be calculated by the following equations:

$$
\rho_{x}=\sum_{i} \frac{d_{i} C_{i}}{A_{i} / N_{a}} b_{i}
$$

where $d_{i}, C_{i}, A_{i}, N_{a}, b_{i}$ is mass density, mass concentration,
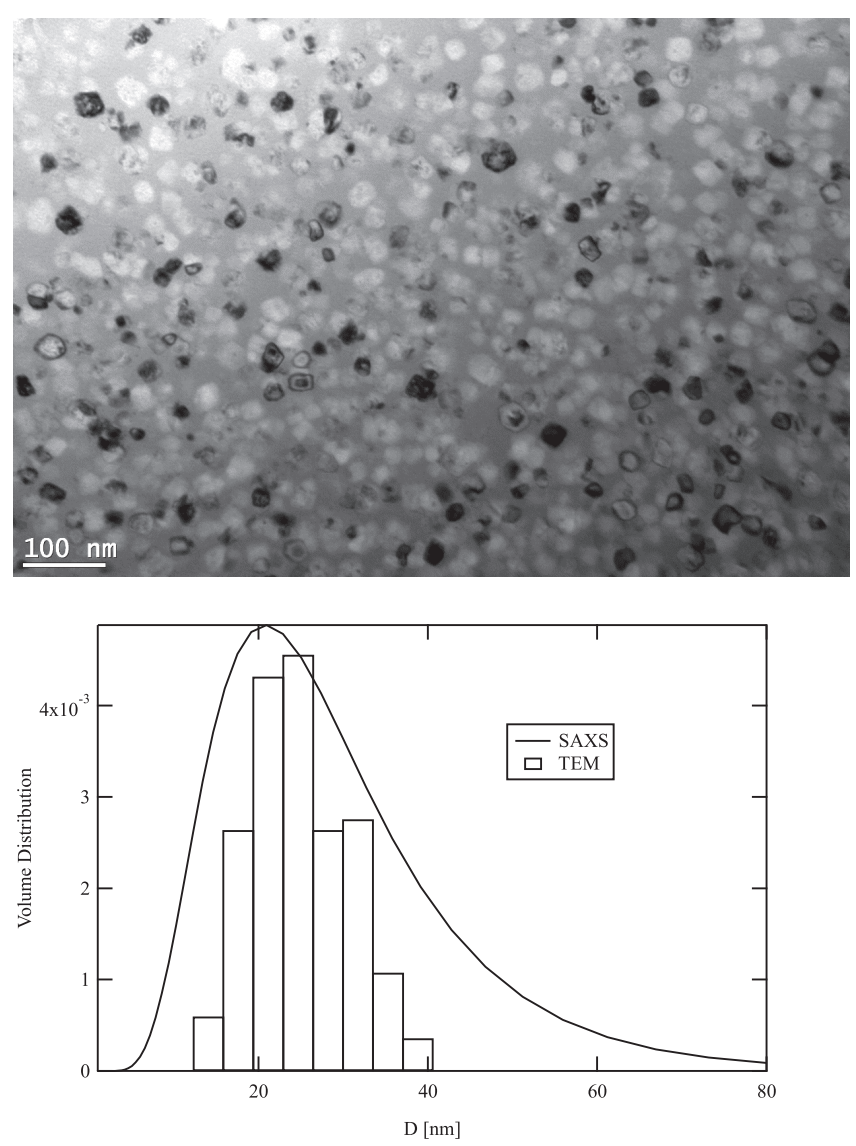

Fig. 4 TEM image and size distribution of $\mathrm{Fe}_{80.7} \mathrm{Cu}_{1.3} \mathrm{Si}_{4} \mathrm{~B}_{14}(20.2 \mu \mathrm{m})$ after annealing. atomic weight, Avogadro constant and coherent scattering length of $i$ element respectively.

As a first approximation, the mass density and nominal composition of the ribbons are used for the residual amorphous phase, and the bcc lattice constant for that of the bcc phase. It is assumed that the contrast of the scattering length density is determined only by the nominal composition, independent of volume fraction. The values are listed in Table 2. While the volume fraction does change depending on the thickness, there is no clear reason why the thickest ribbons give the highest Hc. Returning to profile shape, the thickest ribbons for $\mathrm{Fe}_{80.7} \mathrm{Cu}_{1.3} \mathrm{Si}_{4} \mathrm{~B}_{14}$ and $\mathrm{Fe}_{80.5} \mathrm{Cu}_{1.5} \mathrm{Si}_{4} \mathrm{~B}_{14}$ do not show an interparticle interference peak, though the $\mathrm{V}_{\mathrm{f}}$ values are similar to those of the thinner ribbons. The thickest ribbons of all other compositions also show smaller maxima as compared to thinner ribbons. These results can be explained by the wide distribution of interparticle distances, and therefore, particle size distributions. Figure 7 shows the dependence of $\mathrm{H}_{\mathrm{c}}$ on the size distribution, $\sigma$. All of the thickest

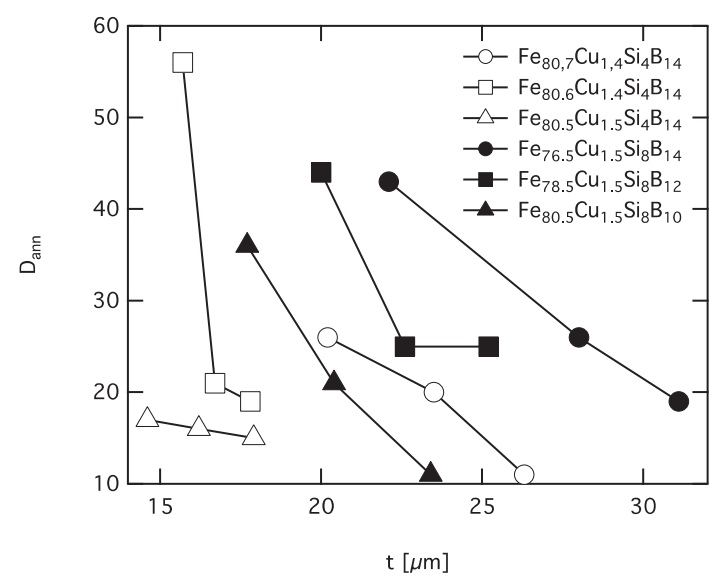

Fig. 5 Average grain size as calculated from SAXS profiles vs sample thickness after annealing.
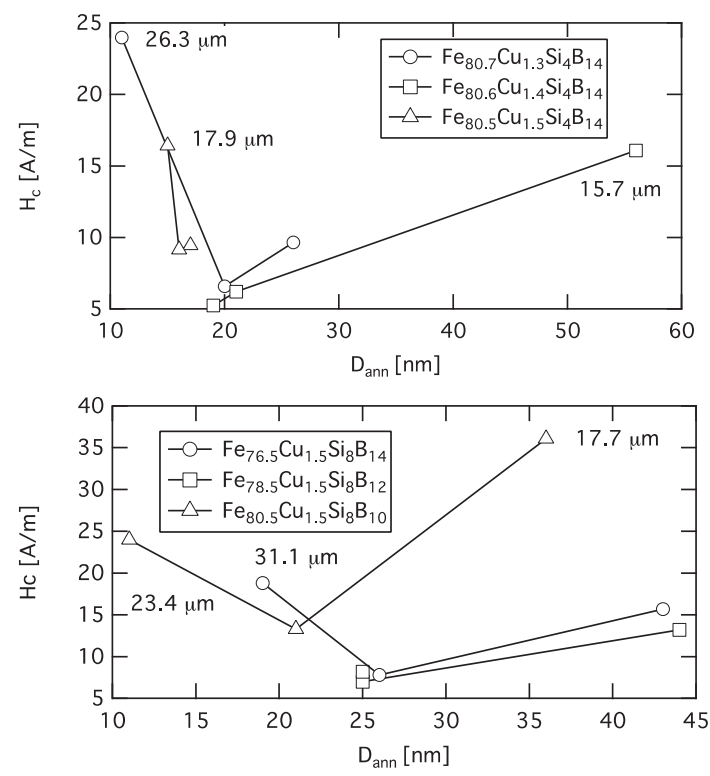

Fig. 6 Coercivity vs average grain size of $\mathrm{Fe}_{80.7-\mathrm{x}} \mathrm{Cu}_{1.3+\mathrm{x}} \mathrm{Si}_{4} \mathrm{~B}_{14}(\mathrm{x}=0,0.1$, 0.2 at\% $)$ and $\mathrm{Fe}_{80.5-\mathrm{x}} \mathrm{Cu}_{1.5} \mathrm{Si}_{8} \mathrm{~B}_{10+\mathrm{x}}(\mathrm{x}=0,2,4$ at $\%)$ after annealing. 
Table 2 Scattering length density $\left(\rho_{\mathrm{x}}\right)$, linear absorption coefficient for radiation used $(\mu)$ and scattering contract $\left(\Delta \rho^{2}\right)$.

\begin{tabular}{ccccc}
\hline Alloy & $\begin{array}{c}\rho_{\mathrm{x}} \\
{\left[10^{10} \mathrm{~cm}^{-2}\right]}\end{array}$ & $\begin{array}{c}\mu_{\mathrm{Cr}} \\
{\left[\mathrm{cm}^{-1}\right]}\end{array}$ & $\begin{array}{c}\mu_{\mathrm{Mo}} \\
{\left[\mathrm{cm}^{-1}\right]}\end{array}$ & $\begin{array}{c}\Delta \rho^{2} \mathrm{FeSi} \\
{\left[10^{20} \mathrm{~cm}^{-4}\right]}\end{array}$ \\
\hline $\mathrm{Fe}_{80,7} \mathrm{Cu}_{1,3} \mathrm{Si}_{4} \mathrm{~B}_{14}$ & 58.5 & 797.1 & 272.1 & 6.6 \\
$\mathrm{Fe}_{80,6} \mathrm{Cu}_{1,4} \mathrm{Si}_{4} \mathrm{~B}_{14}$ & 58.5 & 797.7 & 272.2 & 6.6 \\
$\mathrm{Fe}_{80,5} \mathrm{Cu}_{1,5} \mathrm{Si}_{4} \mathrm{~B}_{14}$ & 58.5 & 798.2 & 272.4 & 6.6 \\
\hline $\mathrm{Fe}_{76,5} \mathrm{Cu}_{1,5} \mathrm{Si}_{8} \mathrm{~B}_{14}$ & 57.7 & 800.3 & 262.5 & 4.2 \\
$\mathrm{Fe}_{78,5} \mathrm{Cu}_{1,5} \mathrm{Si}_{8} \mathrm{~B}_{12}$ & 58.1 & 807.8 & 265.6 & 2.9 \\
$\mathrm{Fe}_{80,5} \mathrm{Cu}_{1,5} \mathrm{Si}_{8} \mathrm{~B}_{10}$ & 59 & 824 & 271.5 & 0.6 \\
\hline
\end{tabular}
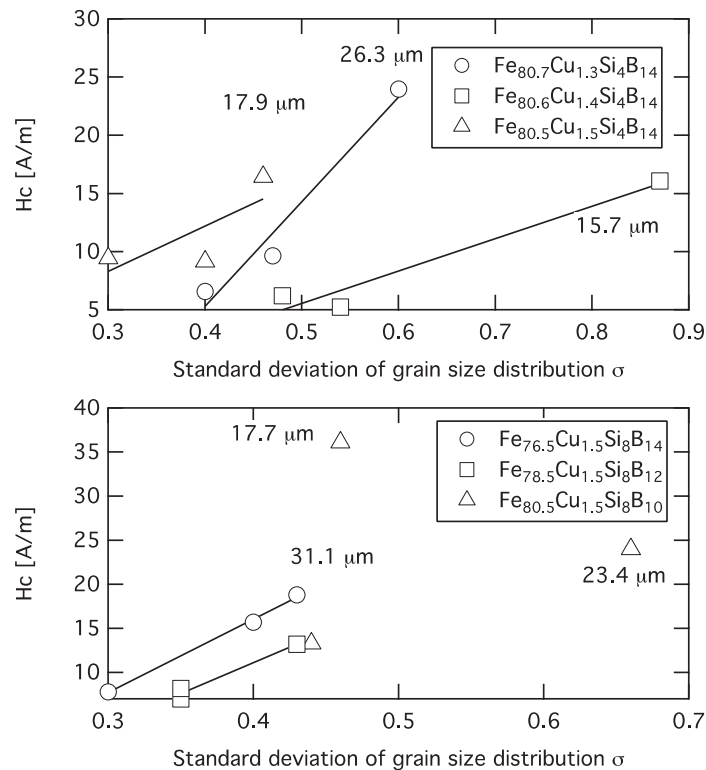

Fig. 7 Coercivity vs standard deviation of grain size of $\mathrm{Fe}_{80.7-\mathrm{x}} \mathrm{Cu}_{1.3+\mathrm{x}} \mathrm{Si}_{4} \mathrm{~B}_{14}(\mathrm{x}=0,0.1,0.2$ at $\%)$ and $\mathrm{Fe}_{80.5-\mathrm{x}} \mathrm{Cu}_{1.5} \mathrm{Si}_{8} \mathrm{~B}_{10+\mathrm{x}}(\mathrm{x}=$ $0,2,4$ at $\%)$ after annealing.

ribbons (except $\mathrm{Fe}_{78.5} \mathrm{Cu}_{1.5} \mathrm{Si}_{8} \mathrm{~B}_{12}$ ) show the largest values. This fact indicates that the number density of the bcc grains is scattered widely in the thickest ribbons, and in some areas, the number of grains in the exchange coupling length is smaller than the value expected from the $\mathrm{D}_{\mathrm{ann}}$.

The size distribution and small size can be explained by comparison to the mechanism in FINEMET-type alloys. Previous studies show that the most important event for high density and uniform nucleation is $\mathrm{Cu}$ clustering prior to bcc phase formation ${ }^{7)}$. In the thickest ribbons, no further nucleation sites form due to post annealing because $\mathrm{Cu}$ clustering occurs before formation of bcc Fe. Therefore, increased volume fraction can only occur by growing, which requires longrange diffusion, which causes slow grain growth. Furthermore, bcc phase formation during quenching occurs nonuni- formly due to heterogeneous nucleation at defects formed during quenching. Some of the thinnest ribbons also show large $\sigma$ values, which indicate that $\mathrm{Cu}$ clustering does not occur effectively. This is possibly due to the kinetics of $\mathrm{Cu}$ clustering as previously studied ${ }^{12)}$, though it is unclear whether it is too fast or too slow.

\section{Summary}

Fe-Si-B-Cu alloys having different compositions and different thicknesses (quenching rates) were studied via SAXS, TEM and XRD. Detailed analysis of SAXS data showed that: - optimum magnetic properties result from the use of not only finer grain sizes, but also smaller size distributions,

- an inverse effect of grain size is observed in as-quenched and annealed samples,

- except in the thickest ribbons, the data can be fit to a random anisotropy model, although the $\mathrm{D}$ dependence is not $\mathrm{D}^{6}$. For the thickest ribbons coercivity can't be predicted by $D_{a n n}$, because the large size distribution is caused by the spatial distribution of the local volume fractions, and

- the large size distribution explains the deviation from $\mathrm{D}^{6}$ because the number of bcc grains is not adequately expressed by a single value of $\mathrm{D}_{\text {ann }}$.

\section{Acknowledgment}

This work was accomplished within the Joint Graduate Program between the Warsaw University of Technology, Poland and the National Institute for Materials Science, Japan. The part of this work was supported by JSPS KAKENHI $15 \mathrm{~K} 06418$.

\section{REFERENCES}

1) G. Herzer: Acta Mater. 61 (2013) 718-734.

2) A. Moses: Electrical steels: past, present and future developments, Physical Science, Measurement and Instrumentation, Management and Education, IEE Proceedings A, vol. 137, (Sep 1990) pp. 233-245.

3) G. Herzer: Magnetics, IEEE Transactions on 25 (1989) 3327-3329.

4) G. Herzer: IEEE Trans. Magn. 26 (1990) 1397-1402.

5) Y. Yoshizawa, S. Oguma and K. Yamauchi: J. Appl. Phys. 64 (1988) 6044-6046.

6) K. Suzuki, A. Makino, A. Inoue and T. Masumoto: J. Appl. Phys. 70 (1991) 6232-6237.

7) K. Hono, D. Ping, M. Ohnuma and H. Onodera: Acta Mater. 47 (1999) 997-1006.

8) M. Ohta and Y. Yoshizawa: J. Phys. D Appl. Phys. 44 (2011) 064004.

9) T. Bitoh, A. Makino, A. Inoue and T. Masumoto: Mater. Trans. 44 (2003) 2011.

10) G. Herzer: Scr. Metall. Mater. 33 (1995) 1741.

11) J. S. Pedersen: J. Appl. Crystallogr. 27 (1994) 595-608.

12) M. Ohnuma, K. Hono, S. Linderoth, J.S. Pedersen, Y. Yoshizawa and H. Onodera: Acta Mater. 48 (2000) 4783-4790. 